OPEN ACCESS

Edited by:

Baris Çalli,

Marmara University, Turkey

Reviewed by:

Sabina Kolbl Repinc,

University of Ljubljana, Slovenia

Elçin Kökdemir Ünşar,

Akdeniz University, Turkey

Mehmet Ali Küçüker

Çanakkale Onsekiz Mart

University, Turkey

*Correspondence:

Zeynep Ceteciog/u zeynepcg@kth.se

Specialty section:

This article was submitted to

Waste Management in

Agroecosystems,

a section of the journal

Frontiers in Sustainable Food Systems

Received: 30 September 2019

Accepted: 17 February 2020

Published: 13 March 2020

Citation:

Elginoz N, Khatami K, Owusu-Agyeman I and Cetecioglu Z (2020) Life Cycle Assessment of an Innovative Food Waste

Management System

Front. Sustain. Food Syst. 4:23. doi: 10.3389/fsufs.2020.00023

\section{Life Cycle Assessment of an Innovative Food Waste Management System}

\author{
Nilay Elginoz, Kasra Khatami, Isaac Owusu-Agyeman and Zeynep Cetecioglu* \\ Department of Chemical Engineering, KTH Royal Institute of Technology, Stockholm, Sweden
}

The aim of this study has been to investigate the environmental impacts of an innovative food waste management system and compare it with landfilling as a conventional waste management option. The investigated system is still in the laboratory research and development phase. Therefore, inventory data of the laboratory scale food waste management system was collected and then up-scaled for life cycle assessment purposes. The proposed system consists of a hygenization reactor followed by a fermenter and then a centrifuge. The system converts food waste into volatile fatty acid-rich supernatant. Functional unit is management of 1 ton food waste. The results indicate that the proposed system is a better option than landfilling in terms of all impact categories. The produced VFA-rich supernatant is supposed to be used as a replacement for methanol in the denitrification process. In one of the impact categories (ozone depletion potential) the avoided burdens are higher than the burdens and the system provides net gain (-2.82E-07 kg R11 eq.). Majority of the environmental burdens in the proposed system are due to heat consumption for hygenization. Including sludge disposal in the investigated system boundary increases the environmental burdens but the burdens are still lower compared to landfilling option.

Keywords: food waste, life cycle assessment, up-scaling, volatile fatty acid, anaerobic digestion

\section{INTRODUCTION}

Food waste is an inevitable portion (34-53\%) of total household waste (Braguglia et al., 2018). It is estimated that more than $30 \%$ of the produced food is wasted globally (Xu et al., 2018), which is $\sim 1.6$ billion tons per year (World Biogas Association, 2018). In the circular city concept, municipal waste management must be improved to greener and sustainable processes, which is a key goal under sustainable development goals (SDGs) for the twenty-first century. To accomplish this, transition into a circular economy which includes resource recovery, reuse and recycling is imperative. Most EU countries are putting in place measures to increase the use of renewable feedstock through a transition into bio-based products. Practical examples include the emissions trading system, policy objectives concerning energy security, stimulation of renewable transportation fuels, imposing tax on $\mathrm{CO}_{2}$ emissions or market mechanisms on fossil fuels to reach self-imposed Paris Agreement targets. Addressing this challenge demands transformation of waste management from traditional disposal methods to next generation carbon-neutral waste disposal technologies and to reduce the amount of food waste European Parliament recommended European Commission to take factual measures to cut down the food waste $50 \%$ by 2025 (Secondi et al., 2015). In the last two decades, EU aims to reduce the landfilled portion of the biodegradable 
waste, however this reduction ended up mostly incineration of this waste (Secondi et al., 2015). The revised EU Waste Framework Directive (2008/98/EC) covers the recommendations on management and treatment of bio-waste to prevent negative environmental consequences that are mainly greenhouse gas emissions during degradation (Monier et al., 2011).

Despite the efforts for transition, landfilling and incineration are still the most common conventional waste disposal approaches; however, anaerobic digestion (AD) is becoming more preferable in the last decade because of biogas production. $\mathrm{AD}$ is not only economically sensible compared to the other alternatives (Xu et al., 2018), but also energy and value-added materials can be produced through this process. Apart from $\mathrm{AD}$, production of volatile fatty acid (VFA) from food waste is an innovative food waste management option. VFAs are the intermediate products of $\mathrm{AD}$ process that have high market value and they can be utilized as building block chemicals or as the raw material in bioplastic production, biodiesel generation and as the carbon source for biological nutrient removal processes (Atasoy et al., 2018). VFAs are produced during the AD after hydrolysis of complex organic matter to smaller molecules by acidonegens. Thus, VFA production can be promoted by shortening the reaction time of an $\mathrm{AD}$ process to prevent methanogenesis. VFA production can also be promoted by operating at $\mathrm{pH}$ above 8.0 or below 6.0 where methanogens activities are inhibited. In some cases, usually lab scale studies, some chemicals can be added to the reactors to inhibit methanogenic activities.

Environmental aspects of food waste management options were compared in the literature and life cycle assessment (LCA) was widely used for evaluation and comparison of food waste management options. In cases from all over the world, conventional food waste disposal methods like landfilling and incineration were compared with alternative methods like $\mathrm{AD}$ and composting. Apart from $\mathrm{AD}$, biofuels can be obtained from food waste through downstream processes such as transesterification of oils and fats, pyrolysis and gasification etc. However, some of the aforementioned processes have not been realized in full-scale yet (Girotto et al., 2015). Therefore, the LCA of food waste management literature focuses on $\mathrm{AD}$ of food waste while investigating alternative food waste management options. Environmental impacts of hybrid systems like AD combined with composting or $\mathrm{AD}$ followed by landfilling were investigated (Righi et al., 2013). Anaerobic co-digestion of food waste and sewage sludge (Righi et al., 2013), comparison of decentralized and centralized management options (Bernstad and la Cour Jansen, 2011), and bioconversion of food waste into larvae by insects (Salomone et al., 2017) have been also studied in terms of life cycle environmental impacts. There are several conclusions obtained from these studies. AD of food waste is more advantageous compared to incineration and landfilling for most of the environmental impact categories (Slorach et al., 2019). AD and composting have lower global warming potential (GWP) compared to incineration but they cause nutrient enrichment and acidification due to digestate application on land (Bernstad and la Cour Jansen, 2011). Decentralized anaerobic co-digestion followed by composting in small plants is an environmentally friendly option due to decreased transportation and energy consumption and energy and nutrient recovery (Righi et al., 2013). If the anaerobic co-digestion is compared to mono digestion, life cycle impact assessment (LCIA) results show that the mono digestion of food waste is a better option (Xu et al., 2015). When in-sink food waste processor, home composting, centralized composting and landfilling is compared using LCA, home composting is the best if it the process is aerobic (Lundie and Peters, 2005). However, AD is more favorable than aerobic composting system (Khoo et al., 2010). While AD is preferred as a treatment option, mostly co-product is biogas. However, producing feedstock like fatty acids is an option worth investigating in terms of environmental impacts. In a recent study, Chen et al. (2017) investigated a novel biorefinery process that produces caproic acid using mixed organic waste and ethanol by chain elongation and concluded that ethanol addition is the major contributor to environmental impacts. Even though alternative methods look promising compared to conventional methods, prevention of the avoidable food waste provides better results to decrease environmental impacts (Bernstad Saravia Schott and Andersson, 2015; Oldfield et al., 2016).

While VFA production from food wastes seems to be an innovative food waste management option, it is important to make early stage environmental assessment to determine its sustainability in the long run. The aim of this study is to determine environmental performance of VFA production from food waste as an innovative food waste management system in early design stage, and to compare its impacts with landfilling option. As mentioned above, there are plenty of LCA studies, which investigate different waste management options, to recover energy and nutrients. However, this study investigates environmental impacts of an emerging food waste management option which produces VFA-rich effluent to use as carbon source in the denitrification process of a wastewater treatment plant (WWTP) as an alternative to conventional sources such as methanol. In this sense, this is the first study to investigate such system. This study also covers the usage of the co-product and closes the loop.

\section{MATERIALS AND METHODS}

The food waste management system, investigated in this study, is still in research and development phase. Therefore, to investigate the system, laboratory scale data obtained from the system developers were used. The laboratory scale data was up-scaled to full scale using the method proposed by Piccinno et al. (2016). This up-scaling method is comprised of five stages, which are given in Figure 1. To apply the method, a simplified plant flow chart is designed based on the laboratory protocol of the investigated system. Each process step is then up-scaled to a conceptual full-scale plant using detailed process calculations. The separately up-scaled process steps are linked in the 4th step. In the last step LCA is performed based on life cycle inventory data generated according to the conceptual full-scale. Application of the method on the current study is explained in detail in the following sections, more information about the method and its application can be found in Piccinno et al. $(2016,2018)$. 


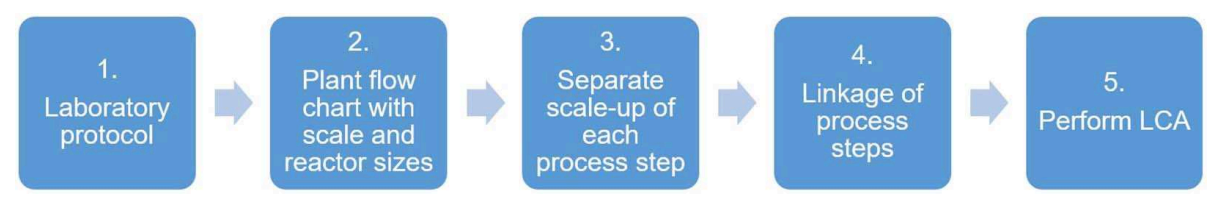

FIGURE 1 | Up-scaling framework steps proposed in Piccinno et al. (2016).

\section{Application of the Up-Scaling Method Stage (1): VFA Production in Laboratory Scale}

Laboratory experiments for VFA production were conducted at the KTH Resource Recovery Laboratory in order to optimize the efficiency of anaerobic digestion of food waste. Food waste was fermented to produce VFA-rich supernatant, which could be used as an external carbon source in denitrification process of wastewater treatment plants. Labscale batch reactor experiments were carried out using food waste as a substrate and digested sludge as an inoculum. The inoculated digested sludge was collected from an $\mathrm{AD}$ of Scandinavian biogas facilities (Stockholm, Sweden) and the food waste was supplied by Himmerfjärden WWTP (Syvab Sweden). The food waste, which was a mixture of household organic waste and the faulty batches of breweries, was hygienized at $71^{\circ} \mathrm{C}$ for $61 \mathrm{~min}$ at Himmerfjärden WWTP prior to use in the experiments.

In the laboratory protocol, the first step was to characterize the inoculum and substrate in terms of total solids, volatile solids, VFA content and $\mathrm{pH}$. Characterization of the inoculum and the substrate is given in Table 1. After characterization, $150 \mathrm{~mL}$ batch reactors in triplicates were filled with the mixture of food waste and inoculum with a food/microbes ratio of $2 \mathrm{~g}$ of chemical oxygen demand per $1 \mathrm{~g}$ volatile solids (COD/VS). The initial $\mathrm{pHs}$ of the reactors were adjusted to alkaline conditions $(\mathrm{pH}$ 10) using $\mathrm{NaOH}$. The batch reactors were then washed with nitrogen, in order to eliminate the oxygen, and placed in an incubator with orbital shaking $(125 \mathrm{rpm})$ for fermentation process under mesophilic condition $\left(35^{\circ} \mathrm{C}\right)$. The experiment was done at hydraulic retention time of 10 days and sampling was done for VFA and COD analysis and the average values were used. Flow chart of the laboratory protocol is given in Figure 2.

\section{Stage (2): Design of a Simplified Plant Flow Chart}

In the scope of this study, a full-scale simplified plant flow chart was formed including hygenization, fermentation and centrifugation. Thermal hygenization batch reactor was conceptually designed to operate $61 \mathrm{~min}$ per day processing $1 \mathrm{~m}^{3}$ food waste. The full-scale fermenter was designed to operate as a fed batch reactor, using food waste as the substrate to produce VFA-rich effluent. The inputs of the fermenter are food waste, sodium hydroxide to adjust the $\mathrm{pH}$ to 10 , heat to maintain the mesophilic conditions, electricity for pumps and mixing the reactor content and lubricating oil for the machinery. Fermenter is followed by a centrifuge to dewater the effluent. The flow chart of the designed plant is given in Figure 3.
TABLE 1 | Characteristics of the food waste and the inoculum.

\begin{tabular}{lcc}
\hline & Food waste & Inoculum \\
\hline TS [mg/L] & 146,233 & 41,800 \\
VS [mg/L] & 132,133 & 30,766 \\
VFA [mg/L] & 6,140 & - \\
$\mathrm{pH}$ & 5.53 & 7.58 \\
TCOD [mg/L] & 215,050 & 73,700 \\
\hline
\end{tabular}

\section{Stage (3): Separate Scale-Up of Each Process Step}

In this stage, inputs and outputs of each unit process were calculated. The variables and equations used for the detailed process calculations are given in Table 2.

\section{Hygenization reactor}

According to Swedish regulations, food waste is heated at $71^{\circ} \mathrm{C}$ for $61 \mathrm{~min}$. The hygenization reactor was designed according to this regulation. Volume of the conceptually designed reactor is $1.1 \mathrm{~m}^{3}$ and the reaction volume is $1 \mathrm{~m}^{3}$. Detailed energy consumption calculation is given in Table 2.

\section{Fermenter}

The reactor was assumed to have a total volume of $13 \mathrm{~m}^{3}$ of which $10 \mathrm{~m}^{3}$ is the working volume. The fermenter was designed to be maintained at $35^{\circ} \mathrm{C}$. The reactor is fed by food waste as $1 \mathrm{~m}^{3} /$ day and hydraulic retention time (HRT) is 10 days in line with the experiments. In the full-scale process, inoculum will be fed only at the initiation of the process and not repeated after the reactor reach the stable conditions. The detailed process calculations were conducted to estimate $\mathrm{NaOH}$ input, energy for heating, stirring, and pumping (Table 2). The heated food waste is stored in a container to cool down before feeding to the fermenter. Therefore, incoming temperature for the fermenter is assumed $35^{\circ} \mathrm{C}$ in the calculations.

There is no fugitive emission because the reactor is operated at a basic $\mathrm{pH}$ of 10 . At $\mathrm{pH} 10$, methanogenic activities are extensively inhibited and therefore, there is no production of methane. Moreover, $\mathrm{CO}_{2}$ which is produced during acidogenesis is dissolved in the fermentation broth due to high $\mathrm{pH}$.

\section{Centrifuge}

In the centrifugation, dewatering of the produced VFA rich effluent requires energy. The maximum amount of consumed energy in centrifugation was estimated as $10 \mathrm{kWh}$ per ton of dry 


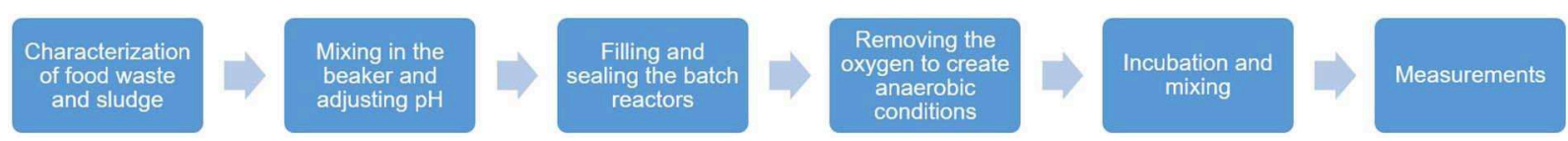

FIGURE 2 | Laboratory protocol of the investigated system.

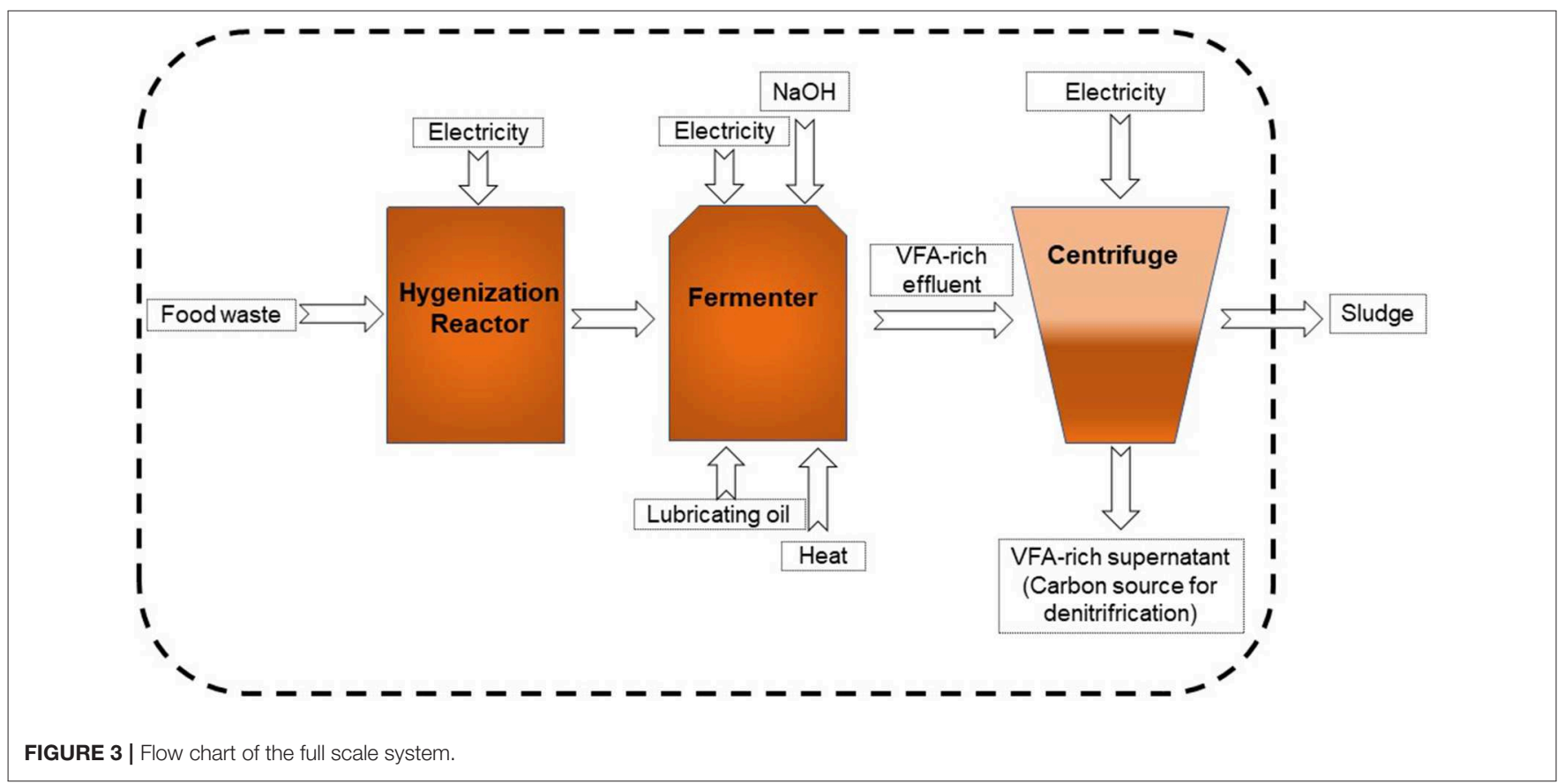

material according to (Piccinno et al., 2016). The products of the centrifugation are VFA-rich supernatant and sludge. Up-scaling calculations are summarized in Table 2.

\section{Stage (4): Linkage of Process Steps}

Daily output of the hygenization reactor is $1 \mathrm{~m}^{3}$ hygenized food waste which is fed into the fermenter. VFA-rich effluent, the output of the fermenter is pumped into the centrifuge to be divided into two phases, supernatant and sludge. Energy of pumping is calculated as the pumping into the fermenter, out of the fermenter and after centrifugation.

The infrastructure of the hygenization reactor, fermenter, and centrifuge was excluded in this study and the study is focused on the operation of the plant. Collection and transportation of the waste is also excluded in this study.

\section{Stage (5): Perform LCA}

In this step, LCA was performed based on life cycle inventory data (Table 3), generated from above calculations. Ecoinvent version 3.3 database was used for background processes and $\mathrm{GaBi}$ software version 8.7 was used for modeling. The modeling choices applied during the LCA are explained below. LCIA results were calculated using CML 2001 methodology January 2016 version. Leiden University Institute of Environmental Science developed CML 2001 methodology. It is a comprehensive method containing characterization factors listed in Guinée et al. (2002) and widely used in LCA studies.

\section{Functional unit}

The main function of the investigated system is food waste management. In similar studies different functional units such as food waste produced by a household in a specified time (Lundie and Peters, 2005) or management of a particular amount of waste (Righi et al., 2013; Tonini et al., 2018; Slorach et al., 2019, etc.) were used. In this study, functional unit is chosen as management of 1 ton food waste.

\section{Avoided burdens}

The produced VFA-rich supernatant is planned to be used as carbon source in the denitrification process of a nearby WWTP. VFA content of the produced supernatant was calculated as $9.78 \mathrm{~kg}$ VFA per day. Usually methanol is used as carbon source in denitrification process. Carbon source amounts are expressed as COD equivalent to a nitrate-nitrogen ratio in the denitrification process. One gram of methanol is equivalent to $1.5 \mathrm{~g}$ COD. However, COD equivalent for VFAs ranges from 1.1 to $2.2 \mathrm{~g}$ $\mathrm{COD} / \mathrm{g} \mathrm{VFA}$, which results in weighted average of about $1.5 \mathrm{~g}$ COD/ g VFA. Although VFAs are known to be more efficient for denitrification than methanol (Liu et al., 2016), the same efficiency is assumed. This means that $1 \mathrm{~g}$ of methanol to be used for denitrification will be equivalent to $1 \mathrm{~g}$ of VFA of needed for 
TABLE 2 | Summary of up-scaling calculations.

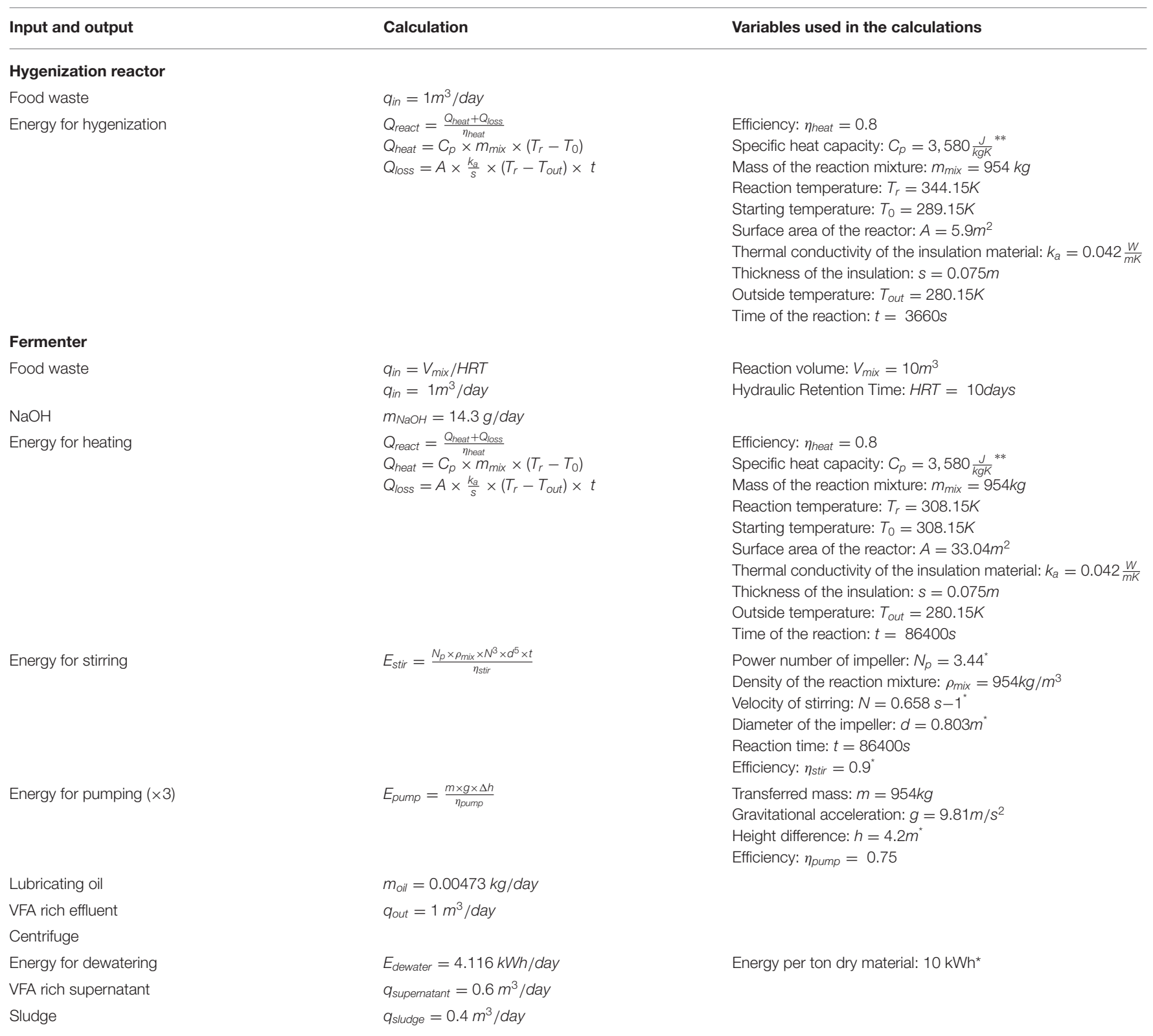

*Piccinno et al. (2016); **Briski et al. (2007).

the same process. Therefore, using effluent of the designed system will avoid the production of $9.78 \mathrm{~kg}$ methanol per day $(10.25 \mathrm{~kg}$ per FU).

\section{By-products}

Sludge produced by the system is considered as a by-product and cut off from the system during the modeling. Digested sludge can be used as a replacement for fertilizer in agriculture. The alternative routes for sludge disposal are incineration and land reclamation. For example, the sludge of Henriksdal and Bromma WWTPs in Stockholm are used for land reclamation of old mine areas and only smaller fraction is used as fertilizer.
In this study, we chose not to give any credits to sludge as a replacement for fertilizer. It is cut off from the system because the treatment facility is not applied in the full scale yet and the usage of future sludge generated in the system is uncertain.

\section{Comparison with landfill option}

When it is not separated from municipal solid waste, food waste mostly ends up in landfills or incineration with the other solid wastes. In this study, the proposed innovative system was compared with landfill option. To calculate environmental burdens of landfill option Ecoinvent version 3.3 process 
TABLE 3 | Aggregated inventory of the investigated system.

\begin{tabular}{lcc}
\hline Input and output & Amount & Unit \\
\hline $\begin{array}{l}\text { Hygenization reactor } \\
\text { Energy for hygenization }\end{array}$ & 68.65 & \\
Fermentor & & $\mathrm{kWh} / \mathrm{FU}$ \\
Food waste & 1.00 & $\mathrm{Ton}(\mathrm{FU})$ \\
$\mathrm{NaOH}$ & 14.99 & $\mathrm{~g} / \mathrm{FU}$ \\
Energy for heating & 16.29 & $\mathrm{kWh} / \mathrm{FU}$ \\
Energy for stirring & 8.73 & $\mathrm{kWh} / \mathrm{FU}$ \\
Energy for pumping & 0.05 & $\mathrm{kWh} / \mathrm{FU}$ \\
Lubricating oil & 4.96 & $\mathrm{~g} / \mathrm{FU}$ \\
Centrifuge & & $\mathrm{kWh} / \mathrm{FU}$ \\
Energy for dewatering & 4.00 & $\mathrm{Ton} / \mathrm{FU}$ \\
VFA rich supernatant & 0.60 & $\mathrm{Ton} / \mathrm{FU}$ \\
Sludge & 0.40 & \\
Avoided burdens & & $\mathrm{kg} / \mathrm{FU}$ \\
VFA content & 10.25 & $\mathrm{~kg} / \mathrm{FU}$ \\
Methanol & 10.25 & \\
\hline
\end{tabular}

"treatment of municipal solid waste, sanitary landfill" process was used and it is assumed that 1 ton of food waste is ended up in landfill.

\section{Limitations of the study}

Main limitation of the study is about considering the same efficiency in laboratory and full scale. VFA production efficiency and yield in a lab-scale experiment can be different from full-scale application due to the fact that lab-scale experiments are done in well-controlled environment which may not be possible in fullscale. For instance, inoculum from well-established reactor was used for the lab-scale experiments but in full-scale plants, it may not be applicable to get such amount of digested sludge to be used as inoculum.

Life cycle inventory of this study is based on conceptually upscaled data and the study is an early stage LCA. Hetherington et al. (2014) points out uncertainty as one of the issues in early stage LCAs. Therefore, giving full details of the calculations is of great importance. Implementing scenario analysis is also an appropriate method to deal with uncertainties while investigating emerging technologies. In this study, scenario analysis applied for disposal of the digested sludge. Investigating other sensitivities like different operating conditions (e.g., thermophilic), food waste with different characteristics and VFA production yield was out of the scope of this study because the study is based on laboratory data available for investigated conditions.

\section{RESULTS AND DISCUSSION}

The main results of the Life Cycle Impact Assessment indicate that the credits given to avoided burden of methanol production is considerably high compared to the system's burdens (Figure 4). In ODP, the avoided burdens are even higher than burdens so

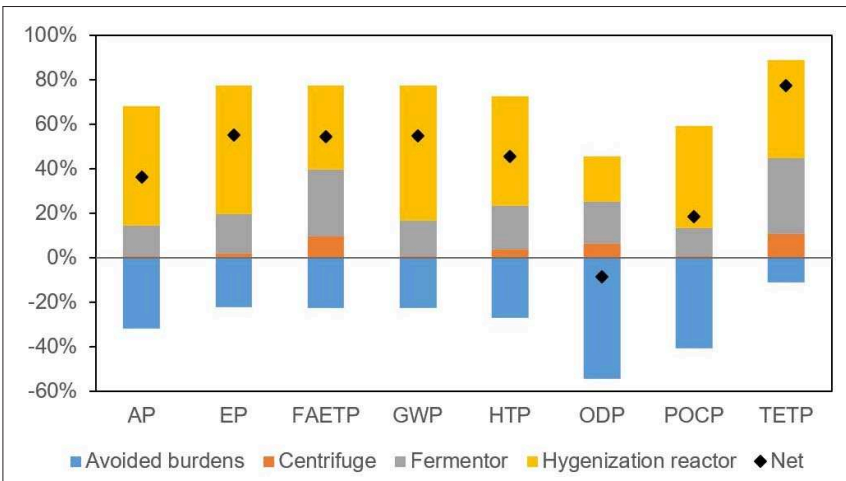

FIGURE 4 | LCIA results of the proposed food waste treatment system. AP, acidification potential; EP, eutrophication potential; FAETP, freshwater aquatic ecotoxicity potential; GWP, global warming potential; HTTP, human toxicity potential; ODP, ozone depletion potential; POCP, photochemical ozone creation potential; TETP, terrestrial ecotoxicity potential.

that the total environmental impact is negative. The produced VFA-rich supernatant is considered to be used as a replacement for methanol in the denitrification process in a nearby WWTP as explained in the avoided burdens section. This means that the environmental burdens sourced from methanol production is deducted from the environmental impacts of the investigated system. Methanol replacement provides credits for each impact category but it is highest for ODP. Ninety-seven percentage of this credit is due to avoiding Halon emissions to air which are related to methanol production.

LCIA results of the proposed system and landfill option are given in Table 4. This comparison shows that the environmental impacts of the proposed system is much lower than landfill with a huge gap in between. However, it must be kept in mind that in this study the efforts for separation and collection of the food waste is not investigated.

This result is in line with Slorach et al. (2019), claiming that the $\mathrm{AD}$ of food waste has lower impacts than landfilling in 15 of 19 impact categories. According to Slorach et al. (2019), AD is worse compared to landfill, only in terrestrial acidification, particulate matter formation and natural land transformation.

Figure 4 shows that the majority of the environmental burdens of the proposed system are sourced from the hygenization reactor and fermenter comes next. The rest is due to electricity consumption in the centrifuge for dewatering. In the hygenization reactor, only energy is consumed therefore, all the burdens from that process is caused by heating energy. The burdens that originate from the fermenter (Figure 5) are mainly due to energy consumption for heating (26-91\%) and energy consumption for stirring (9-71\%). In the model, it is assumed that energy for hygenization and heating is provided from district heating, which is produced from sources other than natural gas and Swedish electricity grid mix is used as electricity source. Currently district heating system is widely employed in Sweden with more than 500 facilities and its share in the energy market increases each year (Werner, 2017). In Sweden the energy sources for district heating are biomass, waste, excess 
TABLE 4 | Comparison of proposed food waste treatment system and landfill option.

\begin{tabular}{|c|c|c|c|}
\hline Impact category & Unit & Proposed system & Landfill \\
\hline $\mathrm{AP}$ & $\mathrm{kg} \mathrm{SO} \mathrm{S}_{2}$ eq. & 7.47E-02 & 3.00E-01 \\
\hline EP & kg Phosphate eq. & $1.75 \mathrm{E}-02$ & $7.63 E+00$ \\
\hline FAETP & kg DCB eq. & 4.37E+00 & $1.94 \mathrm{E}+03$ \\
\hline GWP & $\mathrm{kg} \mathrm{CO} 2$ eq. & $1.46 \mathrm{E}+01$ & $5.73 E+02$ \\
\hline HTP & kg DCB eq. & $5.70 \mathrm{E}+00$ & 1.97E+02 \\
\hline ODP & kg R11 eq. & $-2.82 \mathrm{E}-07$ & $3.15 \mathrm{E}-06$ \\
\hline POCP & kg Ethene eq. & 2.52E-03 & $1.42 \mathrm{E}-01$ \\
\hline TETP & kg DCB eq. & 1.18E-01 & $1.52 \mathrm{E}+00$ \\
\hline
\end{tabular}

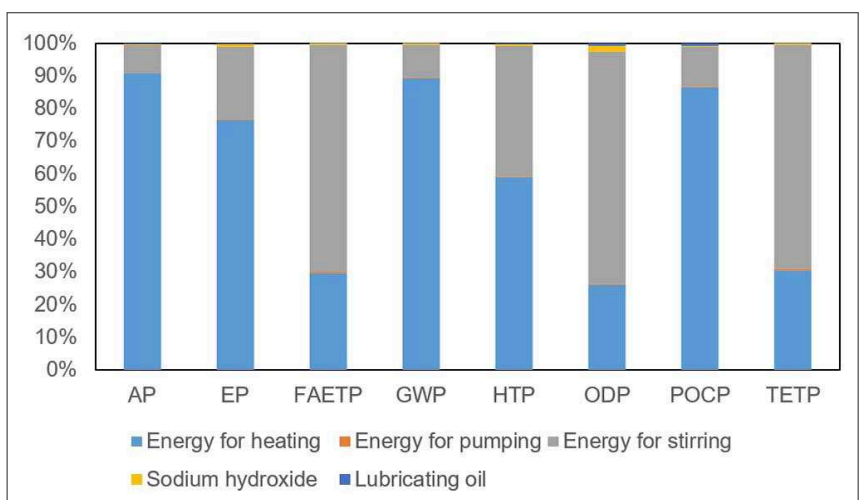

FIGURE 5 | Contribution of each component to impacts sourced from fermenter.

heat, fossil fuels, electricity, ambient heat, recovered gases, and peat. Between 1969 and 2015, the share of fossil fuels decrease substantially while the share of biomass and waste increase (Werner, 2017). Swedish electricity grid mix dataset in Ecoinvent database comprises of $51 \%$ nuclear, $40 \%$ hydropower, $4.4 \%$ wood, $1.3 \%$ oil, and the rest (biogas, hard coal, natural gas, and peat) in small quantities.

When the burdens sourced from hygenization reactor is investigated, it is seen that Sulfur dioxide emissions to air (79\%) due to the fact that district heating cause most of the burdens in AP category. In EP category, 58\% of the burdens are sourced from Phosphate emissions to fresh water. Nickel emissions to fresh water (37\%) and Beryllium emissions (22\%) cause the majority of the FAETP. In GWP, carbon dioxide emissions (92\%), in HTP, arsenic (18\%), Chromium (19\%), Nickel (6\%), and Selenium (12\%) emissions cause most of the burdens. Halon emissions (54\%) contributes to ODP and Sulfur dioxide emissions (56\%) cause POCP. Arsenic (8\%), Chromium (19\%), Mercury (19\%), and Vanadium (24\%) cause TETP.

In a recent unpublished study (Elginoz et al., submitted), VFA production from dairy wastewater was investigated and the results suggested that sodium hydroxide consumption causes a great deal of burdens during the operation of a fermenter to produce VFA. This difference in result is due to low consumption of sodium hydroxide and high production yield in using a similar system in food waste treatment.
As mentioned in the introduction, $\mathrm{AD}$ with biogas recovery is an established bio-waste treatment method. Therefore, the results of this study is compared with Slorach et al. (2019) which presents LCA of AD of household food waste. According to Slorach et al. (2019), treatment of food waste by AD with biogas recovery results with a net gain in terms of 13 out of 19 impact categories. In the mentioned study, credit was given to electricity production and to the digestate usage as fertilizer. Combined heat and power plant following the biogas production in $\mathrm{AD}$ produces the electricity. In the mentioned study treatment of 1 ton food waste results $-39 \mathrm{~kg} \mathrm{CO}_{2}$ eq. while in this study GWP of the system is $14.6 \mathrm{~kg} \mathrm{CO} 2$ eq. Although the system boundaries are different in these two studies-one including collection of the food waste and plant construction- main different in the results is due to impact sources and avoided burdens. In the mentioned study, main GWP sources are fugitive $\mathrm{CH}_{4}$ emissions $(41 \mathrm{~kg}$ $\mathrm{CO}_{2}$ eq.), food waste and digestate transportation $(30 \mathrm{~kg} \mathrm{CO}$ eq.), and $\mathrm{NO}_{2}$ emissions from digestate application $(12 \mathrm{~kg} \mathrm{CO}$ eq.). Transportation and digestate application is not included in this study's system boundaries, and fugitive $\mathrm{CH}_{4}$ emissions does not exist because of the difference in investigated processes. VFA production with fermentation supress $\mathrm{CH}_{4}$ production to enhance VFA production. Therefore, it is possible to say the investigated process prevents the environmental burdens due to fugitive emissions sourced from AD. In this study, GWP (20.7 $\mathrm{CO}_{2}$ eq.) mainly sourced from energy consumption during operation. In both studies, operation conditions are mesophilic. In this study, calculated heat and electricity consumptions per 1 ton waste are 85 and $13 \mathrm{kWh} / \mathrm{t}$, in the mentioned study these values are 82 and $23 \mathrm{kWh} / \mathrm{t}$, respectively.

The comparison also shows that collection of the food waste and transportation of the digestate and giving credits to byproducts make an important contribution while investigating the waste management systems.

When the avoided burdens are investigated, credit given to electricity production ( $-91 \mathrm{~kg} \mathrm{CO}_{2}$ eq.) in the mentioned study is much higher than the credit given to methanol replacement $\left(-6.06 \mathrm{~kg} \mathrm{CO}_{2}\right.$ eq.) in this study. Even the environmental burdens sourced from fugitive emissions during $\mathrm{AD}$ operation is twice the total burdens of the investigated system. However, according to this comparison, the difference in the avoided burdens makes $\mathrm{AD}$ a more advantageous treatment system in terms of GWP compared to the investigated system.

Two things must be considered while evaluating this analysis; (1) The sources for electricity production in the considered grid mix changes the amount of avoided burdens, (2) In the near future, produced VFAs can be recovered with downstream processes and used as feedstock as a replacement of producing VFAs from fossil sources. This development would change the replaced product and hence the avoided burdens. Therefore, it is worth investigating this option in the future studies.

\section{Scenario Analysis}

Scenario analysis is a useful tool when the uncertainty is high such as this case in which up-scaling calculations are applied instead of collecting full-scale data. In the base scenario, sludge sourced from the centrifuge is excluded from the study due 
TABLE 5 | Comparison of proposed system, landfill following proposed system, and landfill.

\begin{tabular}{|c|c|c|c|c|}
\hline Impact category & Unit & Proposed system & Proposed system followed by landfill & Landfill \\
\hline AP & $\mathrm{kg} \mathrm{SO}_{2}$ eq. & 7.47E-02 & 8.40E-02 & 3.00E-01 \\
\hline EP & kg Phosphate eq. & $1.75 \mathrm{E}-02$ & 1.99E-02 & 7.63E +00 \\
\hline FAETP & kg DCB eq. & 4.37E+00 & $4.51 \mathrm{E}+00$ & $1.94 \mathrm{E}+03$ \\
\hline GWP & kg CO2 eq. & $1.46 \mathrm{E}+01$ & $1.59 \mathrm{E}+01$ & $5.73 \mathrm{E}+02$ \\
\hline HTP & kg DCB eq. & $5.70 \mathrm{E}+00$ & $6.15 \mathrm{E}+00$ & 1.97E+02 \\
\hline ODP & kg R11 eq. & $-2.82 \mathrm{E}-07$ & $-9.31 E-08$ & 3.15E-06 \\
\hline POCP & kg Ethene eq. & $2.52 \mathrm{E}-03$ & 3.97E-03 & 1.42E-01 \\
\hline TETP & kg DCB eq. & $1.18 \mathrm{E}-01$ & $1.22 \mathrm{E}-01$ & $1.52 \mathrm{E}+00$ \\
\hline
\end{tabular}

to the fact that disposal scenario is being highly uncertain. In this part, the sludge is considered to be send to landfill as a worst case scenario to see how much this decision affects the total results.

The result of the scenario analysis (Table 5) reveals that even if the digester sludge is landfilled it is still much better than landfilling the food waste option. However, in terms of environmental impacts, if residual sludge is landfilled, the impacts increase from 3 to $57 \%$.

\section{CONCLUSION}

The treatment of food waste with AD process producing VFAs provides positive impact in ODP when the produced VFArich supernatant is used as a replacement for methanol in the denitrification process of a nearby WWTP. Comparison of the proposed system's environmental impacts with landfilling, it is seen that the proposed system is a much better option.

Energy consumption for hygenization and fermentation are the major sources of the environmental impacts of the proposed system. Energy for stirring, lubricating oil and sodium hydroxide consumption barely adds any environmental burdens to the system.

Including or excluding the sludge disposal methods has an impact on the results. Therefore, before application of the system in full-scale, the sludge characteristics, and best disposal options must be investigated and evaluated.

There is a need for investigation of best possible disposal options for food waste. In the future studies, the proposed system can be exclusively compared to conventional AD with biogas production and other options like composting and incineration

\section{REFERENCES}

Atasoy, M., Owusu-Agyeman, I., Plaza, E., and Cetecioglu, Z. (2018). Biobased volatile fatty acid production and recovery from waste streams: current status and future challenges. Bioresour. Technol. 268, 773-786. doi: 10.1016/j.biortech.2018.07.042

Bernstad Saravia Schott, A., and Andersson, T. (2015). Food waste minimization from a life-cycle perspective. J. Environ. Manage. 147, 219-226. doi: 10.1016/j.jenvman.2014.07.048 to determine the best option. This investigation must be countryspecific due to the fact that the credits given to electricity production during $\mathrm{AD}$ with biogas production and incineration is country-specific.

\section{DATA AVAILABILITY STATEMENT}

All datasets generated for this study are included in the article/supplementary material.

\section{AUTHOR CONTRIBUTIONS}

NE has applied the up-scaling method to the laboratory scale system, conducted the life cycle assessment including the analysis and interpretation of the results, and wrote the manuscript. KK provided the laboratory scale data, took part in the design and estimations of the full-scale system and in writing the manuscript, and proof read the manuscript. IO-A designed the full-scale system based on laboratory protocol, took part in up-scaling estimations and calculations, and proof read the manuscript as a native English speaker. ZC designed the study as senior author, took part in design of the full scale system and improved, and proof read the manuscript.

\section{FUNDING}

This study was funded by the Swedish Research Council Formas in the scope of the project Methodology for environmental sustainability assessment in the early design stage of a resource recovery system (MENToR) 2018-01297. Manage. 31, 1879-1896. doi: 10.1016/j.wasman.2011.02.026

Braguglia, C. M., Gallipoli, A., Gianico, A., and Pagliaccia, P. (2018). Anaerobic bioconversion of food waste into energy: a critical review. Bioresour. Technol. 248, 37-56. doi: 10.1016/j.biortech.2017.06.145

Briski, F., Vukovic, M., Papa, K., Gomzi, Z., and Domanovac, T. (2007). Modelling of composting of food waste in a column reactor. Chem. Pap. 61, 24-29. doi: 10.2478/s11696-006-0090-0 
Chen, W.-S., Strik, D. P. T. B., Buisman, C. J. N., and Kroeze, C. (2017). Production of caproic acid from mixed organic waste: an environmental life cycle perspective. Environ. Sci. Technol. 51, 7159-7168. doi: 10.1021/acs.est.6b06220

Girotto, F., Alibardi, L., and Cossu, R. (2015). Food waste generation and industrial uses: a review. Waste Manage. 45, 32-41. doi: 10.1016/j.wasman.2015.06.008

Guinée, J. B., Gorrée, M., Heijungs, R., Huppes, G., Kleijn, R., Koning, A., et al. (2002). Handbook on Life Cycle Assessment. Operational guide to the ISO Standards. I: LCA in Perspective. IIa: Guide. IIb: Operational annex. III: Scientific background. Dordrecht: Kluwer Academic Publishers, 692.

Hetherington, A. C., Borrion, A. L., Griffiths, O. G., and McManus, M. C. (2014). Use of LCA as a development tool within early research: challenges and issues across different sectors. Int. J. Life Cycle Assess. 19, 130-143. doi: 10.1007/s11367-013-0627-8

Khoo, H. H., Lim, T. Z., Tan, R. B. H. (2010). Food waste conversion options in Singapore: environmental impacts based on an LCA perspective. Sci. Total Environ. 408, 1367-1373. doi: 10.1016/j.scitotenv.2009.10.072

Liu, F., Tian, Y., Ding, Y., and Li, Z. (2016). The use of fermentation liquid of wastewater primary sedimentation sludge as supplemental carbon source for denitrification based on enhanced anaerobic fermentation. Bioresour. Technol. 219, 6-13. doi: 10.1016/j.biortech.2016.07.030

Lundie, S., and Peters, G. M. (2005). Life cycle assessment of food waste management options. J. Clean. Prod. 13: 275-286. doi: 10.1016/j.jclepro.2004.02.020

Monier, V., Shailendra, M., Escalon, V., O'Connor, C., Gibon, T., Anderson, G., et al. (2011). Preparatory Study on Food Waste across EU 27. European Commission (DG ENV) Directorate C-Industry. 2010. Final Report. ISBN: 978-92-79-22138-5.

Oldfield, T. L., White, E., and Holden, N. M. (2016). An environmental analysis of options for utilising wasted food and food residue. J. Environ. Manage. 183, 826-835. doi: 10.1016/j.jenvman.2016.09.035

Piccinno, F., Hischier, R., Seeger, S., and Som, C. (2016). From laboratory to industrial scale: a scale-up framework for chemical processes in life cycle assessment studies. J. Clean. Prod. 135:1085-1097. doi: 10.1016/j.jclepro.2016.06.164

Piccinno, F., Hischier, R., Seeger, S., and Som, C. (2018): Predicting the environmental impact of a future nanocellulose production at industrial scale: application of the life cycle assessment scale-up framework. J. Clean. Prod. 174, 283-295. doi: 10.1016/j.jclepro.2017.10.226

Righi, S., Oliviero, L., Pedrini, M., Buscaroli, A., and Casa, C. D. (2013). Life Cycle Assessment of management systems for sewage sludge and food waste: centralized and decentralized approaches. J. Clean. Prod. 44, 8-17. doi: 10.1016/j.jclepro.2012.12.004

Salomone, R., Saijaa, G., Mondello, G., Giannetto, A., Fasulo, S., and Savastano, D. (2017). Environmental impact of food waste bioconversion by insects: application of Life Cycle Assessment to process using Hermetia illucens. J. Clean. Prod. 140, 890-905. doi: 10.1016/j.jclepro.2016.06.154

Secondi, L., Principato, L., and Laureti, T. (2015). Household food waste behavior in EU-27 countries: a multilevel analysis. Food Policy 56, 25-40. doi: 10.1016/j.foodpol.2015.07.007

Slorach, P. C., Jeswani, H. K., Cuéllar-Franca, R., Azapagic, A., Slorach et al. (2019). Environmental sustainability of anaerobic digestion of household food waste. J. Environ. Manage. 236, 798-814. doi: 10.1016/j.jenvman.2019. 02.001

Tonini, D., Albizzati, P. F., and Astrup, T. F. (2018). Environmental impacts of food waste: learnings and challenges from a case study on UK. Waste Manage. 76, 744-766 doi: 10.1016/j.wasman.2018. 03.032

Werner, S. (2017). District heating and cooling in Sweden. Energy 126, 419-429. doi: 10.1016/j.energy.2017.03.052

World Biogas Association (2018). Global Food Waste Management: An Implementation Guide for Cities. London: World Biogas Association.

Xu, C., Shi, W., Hong, J., Zhang, F., and Chen, W. (2015). Life cycle assessment of food waste-based biogas generation. Renew. Sustain. Energy 49, 169-177. doi: 10.1016/j.rser.2015.04.164

Xu, F., Li, Y., Ge, X., Yang, L., and Li, Y. (2018). Anaerobic digestion of food waste - challenges and opportunities. Bioresour. Technol. 247, 1047-1058. doi: 10.1016/j.biortech.2017. 09.020

Conflict of Interest: The authors declare that the research was conducted in the absence of any commercial or financial relationships that could be construed as a potential conflict of interest.

Copyright (c) 2020 Elginoz, Khatami, Owusu-Agyeman and Cetecioglu. This is an open-access article distributed under the terms of the Creative Commons Attribution License (CC BY). The use, distribution or reproduction in other forums is permitted provided the original author(s) and the copyright owner(s) are credited and that the original publication in this journal is cited, in accordance with accepted academic practice. No use, distribution or reproduction is permitted which does not comply with these terms. 